\title{
The late Pleistocene horned crocodile Voay robustus (Grandidier \& Vaillant, 1872) from Madagascar in the Museum für Naturkunde Berlin
}

\author{
Constanze Bickelmann ${ }^{1}$ and Nicole Klein*,2 \\ ${ }^{1}$ Museum für Naturkunde Berlin, Invalidenstraße 43, 10115 Berlin, Germany. \\ 2 Steinmann-Institut für Geologie, Paläontologie und Mineralogie, Universität Bonn, Nußallee 8, 53115 Bonn, Germany. \\ E-mail: nklein@uni-bonn.de
}

Received 23 May 2008

Accepted 27 August 2008

Published 20 February 2009

\section{Key Words}

Crocodylia

late Quaternary

ecology

extinction

\begin{abstract}
Crocodylian material from late Pleistocene localities around Antsirabe, Madagascar, stored in the collection of the Museum für Naturkunde, Berlin, was surveyed. Several skeletal elements, including skull bones, vertebrae, ribs, osteoderms, and limb bones from at least three large individuals could be unambiguously assigned to the genus Voay Brochu, 2007. Furthermore, the simultaneous occurrence of Voay robustus Grandidier \& Vaillant, 1872 and Crocodylus niloticus Laurenti, 1768 in Madagascar is discussed. Voay robustus and Crocodylus niloticus are systematically separate but similar in stature and size, which would make them direct rivals for ecological resources. Our hypothesis on the extinction of the species Voay, which was endemic to Madagascar, suggests that C. niloticus invaded Madagascar only after V.robustus became extinct.
\end{abstract}

\section{Introduction}

A diverse subfossil vertebrate fauna from Madagascar has been described from around 30 localities (Samonds 2007). The Pleistocene fauna contained several megafaunal elements, including a large crocodile, giant tortoises, giant lemurs, pigs, pygmy hippos, and elephant birds (Burney et al. 1997). An island-wide extinction event eliminated the entire megafauna of the Holocene (Burney et al. 1997). The extinction was mainly caused by conspicuous changes in climate and vegetation, which already began in the late Pleistocene (Burney et al. 2004). In addition, human activity from the late Holocene onwards has also played a large role (Burney et al. 2004; Brochu 2007).

Besides a giant fossa and a giant eagle, a large crocodile, Voay robustus (Grandidier \& Vaillant, 1872), had long been one of the top predators in the Madagascan ecosystem (Brochu 2006, 2007; Goodman \& Ravoavy 1993). Some authors argue that the Nile crocodile, Crocodylus niloticus Laurenti, 1768, coexisted with $V$. robustus in Madagascar and that it is the only survivor of the Pleistocene megafaunal extinction event (Burney et al. 1997). However, there is some evidence from the fossil record that the Nile crocodile was not in fact a member of the Pleistocene megafauna of Madagascar (Brochu 2007). Although C. niloticus and V. robustus were not closely related (Brochu 2007), their overall nature was similar, except for the more robust stature of Voay robustus. Both species were generalists of similar body size, which was around 3.5 to $4.0 \mathrm{~m}$ (Glaw \& Vences 1994; Kuchling et al. 2004; Brochu 2001). Thus, the question arises if the Nile crocodile inhabited Madagascar while Voay was still present there and simply outcompeted V.robustus, or another scenario could be that C.niloticus had not established a viable population in Madagascar before V. robustus became extinct.

The aim of the current study is to describe the material from the late Pleistocene of Madagascar in the collection of the Museum für Naturkunde Berlin (MfN) and assign it to a valid taxon. Furthermore, a new extinction scenario of the late Pleistocene predator Voay robustus is discussed.

\footnotetext{
* Corresponding author
} 


\section{Material and locality}

Material. Several skeletal elements, including skull bones, limb bones, vertebrae, ribs, and osteoderms from at least three large individuals can be assigned to Voay robustus. The referred material was bought by the Museum für Naturkunde, Berlin, in 1898. Since then, the material has been stored in the MfN collection.

Due to differences in color and preservation of these bones, it is likely that the fossils do not come from the same locality, or at least not from the same place or level, but from at least two different ones. Another possibility could be that the bones of the two larger individuals, which are more reddish in color, opposed to the yellowish color of the bones belonging to a smaller individual, were more exposed to the sun. However, this is difficult to verify because the remains were not collected first hand.

On the basis of femur size range (MB.R.4106-4109: 270-335 mm) the total body length of the individuals is estimated to have been around $3.5 \mathrm{~m}$ to $4.0 \mathrm{~m}$ (Farlow et al. 2005). The smooth shaft surface and the deep and long ridges on the surface of the proximal and distal end of the humeri, indicate a rather advanced age of the individuals (Tumarkin-Deratzian et al. 2006). In order to exclude the possibility that the MfN material belongs to C. niloticus, one specimen (ZMB 36650 ) of this species was used for comparison.

Locality and stratigraphy. As indicated on an old label, the skeletal remains come from late Pleistocene deposits in Antsirabe, Betsileo, Madagascar. Antsirabe is located in central Madagascar, on the Central High Plateau. The region in the east of Antsirabe contains several paleontological sites (Burney et al. 2004; pers. comm. Samonds 2008). A lot of the old locality information is actually referring to a region around Antsirabe and not to one specific locality. In fact, fossils were often collected in localities up to $100 \mathrm{~km}$ from the city Antsirabe (pers. comm. Samonds 2008). According to Burney et al. (2004), several sites near Antsirabe are dated to 17,100-19,250 years BP with the help of AMS (Accelerator Mass Spectrometry) radiocarbon dating of bird bones.

Little is published on the fossil fauna from these sites, except for findings of birds (Goodman \& Ravoavy 1993) and crocodiles (Grandidier 1872; Grandidier \& Vaillant 1872; Mook 1921): From what is preserved in a few localities, Voay robustus seemed to have been a common resident in Madagascar (Brochu, 2000; Burney et al.
2004). On the contrary, so far Crocodylus niloticus had not been found in deposits dated to a period before the settlement of humans in Madagascar (Brochu 2007).

The sedimentology around Antsirabe describes a paleolake situation in a wetland area (Burney et al. 2004). The altitude of Antsirabe is about $1500 \mathrm{~m}$, which is rather high. The high altitude implies a relatively cool climate in the past, which is still the case today.

Institutional abbreviations for catalogue numbers. MB - Museum für Naturkunde, Berlin, paleontological collection; ZMB - Museum für Naturkunde, Berlin, zoological collection.

\section{Systematic Paleontology}

Order Crocodylia Owen, 1842

Family Crocodylidae Cuvier, 1807

Subfamily Osteolaeminae Brochu, 2003

Voay Brochu, 2007

\section{Voay robustus (Grandidier \& Vaillant, 1872)}

Neotype. MCZ 1006 (Brochu 2007)

Type locality and horizon. Antsirabe, late Quaternary, Madagascar (Grandidier \& Vaillant 1872).

Diagnosis (from Brochu 2007: 840). Osteolaemine crocodylid with a prominent triangular crest at the posterolateral corner of each squamosal and a pair of oval bosses on the frontal between the orbits. Supratemporal fenestrae constricted, with no dorsal fossae. Nasals form thin processes that penetrate the narial rim, but premaxillae approach each other closely behind external naris. Surangular-angular suture intersects external mandibular fenestra at the posteriormost end laterally and does not pass anteriorly along the ventral margin of the fenestra (reversal of derived feature in crocodylids). Circular boss on medial surface of splenial. Vaulted premaxillary and maxillary palate surfaces. Shares everted choanal margin (choanal 'neck') and lateral extension of squamosal on to quadrate ramus with other osteolae-
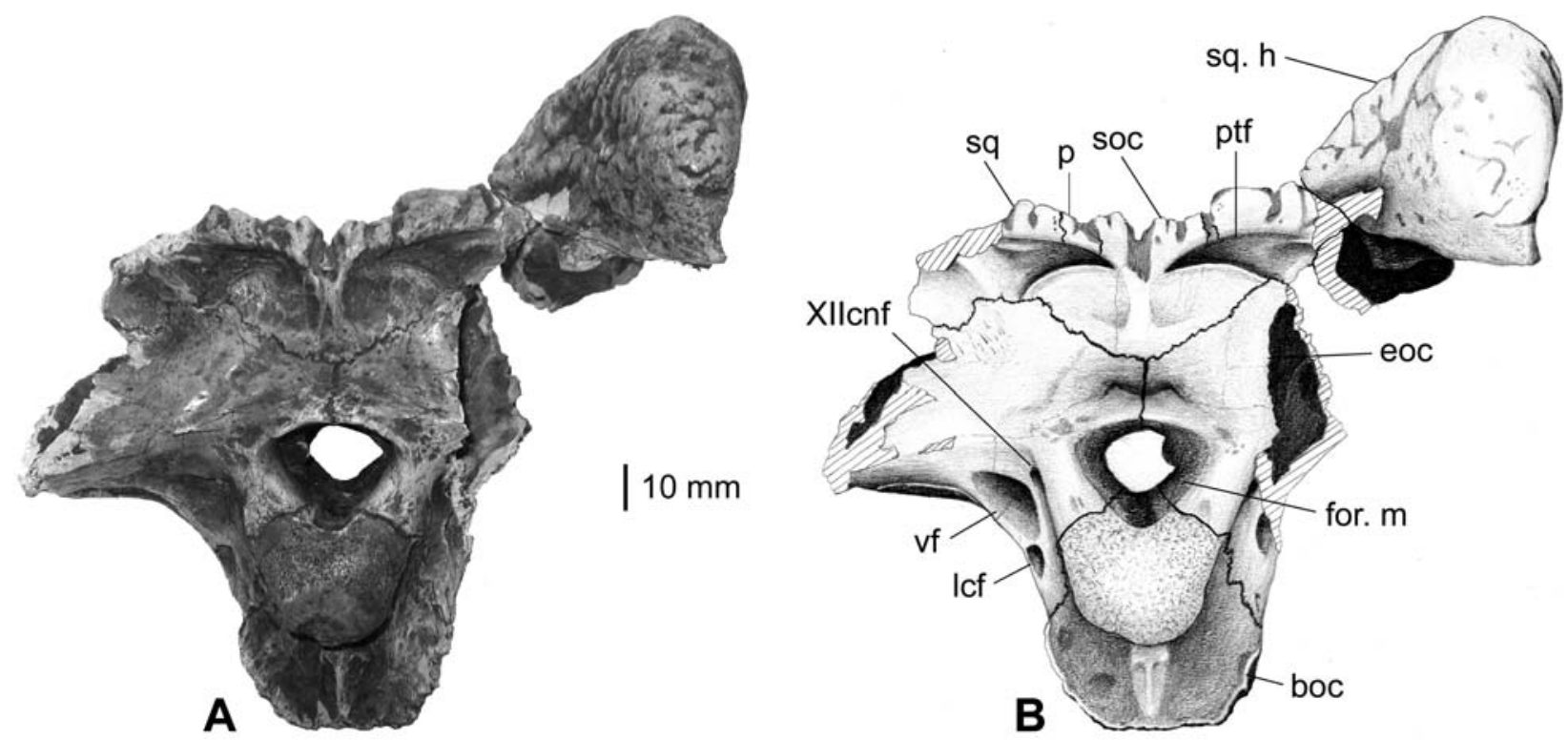

Figure 1. Occiput of Voay robustus (Grandidier \& Vaillant, 1872). Note the special squamosal horn. A. Photograph of specimens MB.R.4124 and MB.R.4127.3 in postaxial view; B. Drawing of A; boc - basioccipital; eoc - exoccipital; for. m - foramen magnum; lef - lateral carotid foramen; p - parietal; ptf - posttemporal foramen; soc - supraoccipital; sq - squamosal; sq. h squamosal horn; vf - vagus foramen; XIIcnf - XIIth cranial nerve foramen. 
mines; shares broad supraacetabular buttress and altirostral skull with Osteolaemus.

Referred specimens. MB.R.4090-MB.R.4607 (Figs 1-6).

\section{Description}

Skull bones. In MB.R.4124, an incomplete but articulated occipital region is preserved (Fig. 1). The supraoccipital is a small element. Its reduction in size excludes it from entering the foramen magnum (Romer 1956). Its dorsal surface, which is triangular in shape, is highly sculptured (Romer 1956). The occipital surface is also triangular in outline. Laterally, it is restricted by two deep incisions. These are the posttemporal foramina. The sutures of the supraoccipital with the parietal, the squamosals and the exoccipitals are distinct and zigzag-shaped. Both exoccipitals are partly preserved. Together with the basioccipital, these enclose the foramen magnum. Above the dorsal boundary with the foramen magnum, there is an elevated ridge extending along both exoccipitals. On the left exoccipital, three foramina are identifiable, whereby the lateral carotid foramen is located ventral to a larger oval depression containing the vagus foramen and laterally to the opening for the XIIth cranial nerve. Both exoccipitals form zigzag sutures to all neighboring elements. The basioccipital, which is located beneath the foramen magnum, is complete. The upper part of this element forms the occipital condyle. Ventrally, the occipital surface bears a slightly heightened crest, the sagittal crest. Its top part is broken off. Also, the lateral margins are slightly elevated. Its sutures with the exoccipitals are well preserved and zigzag-shaped. On the highly sculptured skull table, only the posterior part of the parietal is preserved. It lies between both squamosals and the supraoccipital. The preserved antero-lateral sides extend upwards and form a ridge, together with the squamosals. These are the medial margins of the supratemporal

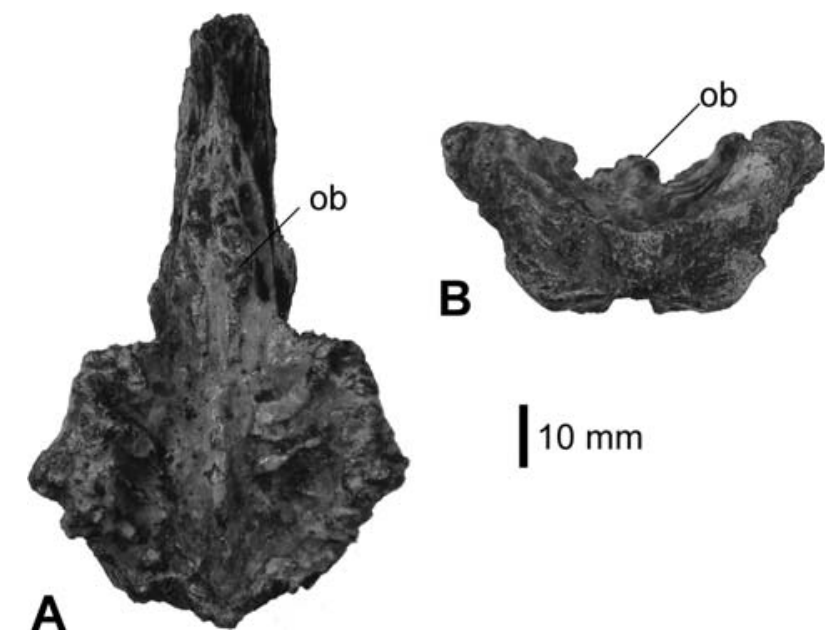

Figure 2. Frontal of Voay robustus (Grandidier \& Vaillant, 1872) (MB.R.4127.3). Note the oval boss on the right side of the anterior part. A. Photograph in dorsal view; B. Photograph in postaxial view; ob - oval boss. fenestrae. With the lateral margins reaching upwards, the mid part of the parietal appears depressed. The area around the supratemporal fossa is not preserved. Only small parts of each squamosal are preserved. The right squamosal continues the ridge, initiated by the parietal, at the margin of the supratemporal fenestra. Postero-laterally, the left quadrate is fragmentarily preserved. In ventral view, a small portion of the basisphenoid is preserved.

MB.R.4127.3 is a squamosal horn that fits perfectly onto the right squamosal of MB.R.4124 (Fig. 1), indicating that they belong to the same individual. The squamosal horn is highly elevated and triangular in shape. The posterior part reaches behind the occipital

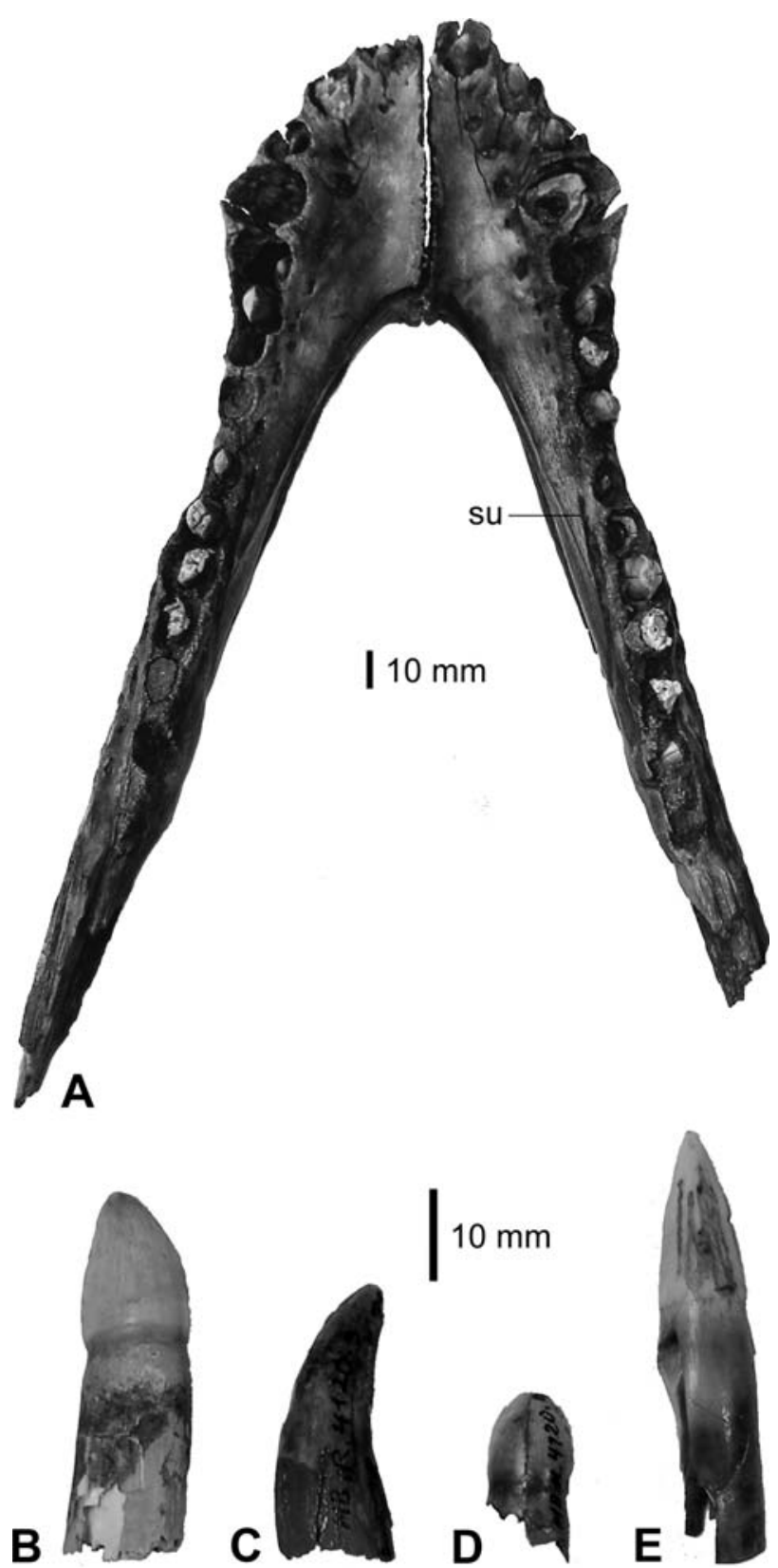

Figure 3. Photographs of elements from the lower jaw of Voay robustus (Grandidier \& Vaillant, 1872). A. Specimen MB.R.4123, both dentaries, in internal view, with the sulcus indicated; B-E. Isolated teeth (MB.R.4120.1-3, 9); su - sulcus. 
surface. Anteriorly, the suture to and a small part of the postorbital are preserved. Laterally, there is a groove, which was termed 'lateral squamosal groove' by Brochu (2007). It forms the edge above the external otic recess, which contains the external otic aperture (Brochu 2007). Postero-dorsally, the lateral squamosal groove deepens markedly. The surface of the lateral squamosal groove is smooth, whereas the rest of the squamosal horn is sculptured with small pits and grooves.

The frontal (MB.R.4128.1) is complete, including all its sutures to adjacent bones (Fig. 2). It has a pentagonal-shaped posterior part and a slender anterior process, with both processes being equally long. On the anterior part, which would lie between the prefrontals, there is one oval boss on the right side (Fig. 2A, B). On the posterior part, the lateral margins with the orbits reach upwards and form ridges at the orbit margins (Fig. 2B). Thus, the middle appears depressed. The dorsal surface is heavily sculptured with small pits and grooves (Fig. 1), but the ventral surface is smooth. On the ventral side of the frontal, there is a trough running anteroposteriorly, which houses tracts serving for olfaction (Brochu 2007).
Lower jaw. A nearly complete lower jaw is preserved (Fig. 3A), the shape of which implies the presence of an elongate snout. Both dentaries (MB.R.4123) are almost completely preserved. Posteriorly on each dentary, a small piece enclosing the external mandibular fenestra is broken off. The symphyseal angle measures around $40^{\circ}$. The outer surface is highly sculptured with small pits and grooves. Interiorly, there is the narrow Meckelian groove. The mandibular symphysis (MB.R.4121 and MB.R.4123) extends to the level of the seventh alveolus. Medially, a shallow sulcus extends from the ninth alveolus back towards the 11th alveolus, with the sulcus being most prominent in the area around the 11th alveolus. Each dentary bears 14 alveoli. The alveoli are rounded-oval and some bear fragmentary teeth. Between the eighth and ninth alveolus, there is a distinct gap. The largest tooth is the fourth and its alveolus is not confluent with the one of the third. In Figure 3B-E, four teeth (MB.R.4120.1-3,9) are depicted. The teeth are conical and somewhat mediolaterally compressed.

Both angulars are completely preserved. Figure 4 shows a left angular (MB.R.4122.2). In external (Fig. 4A) and internal view (Fig. 4B, C), the ventromedial surface of the Meckelian groove, initiated by the
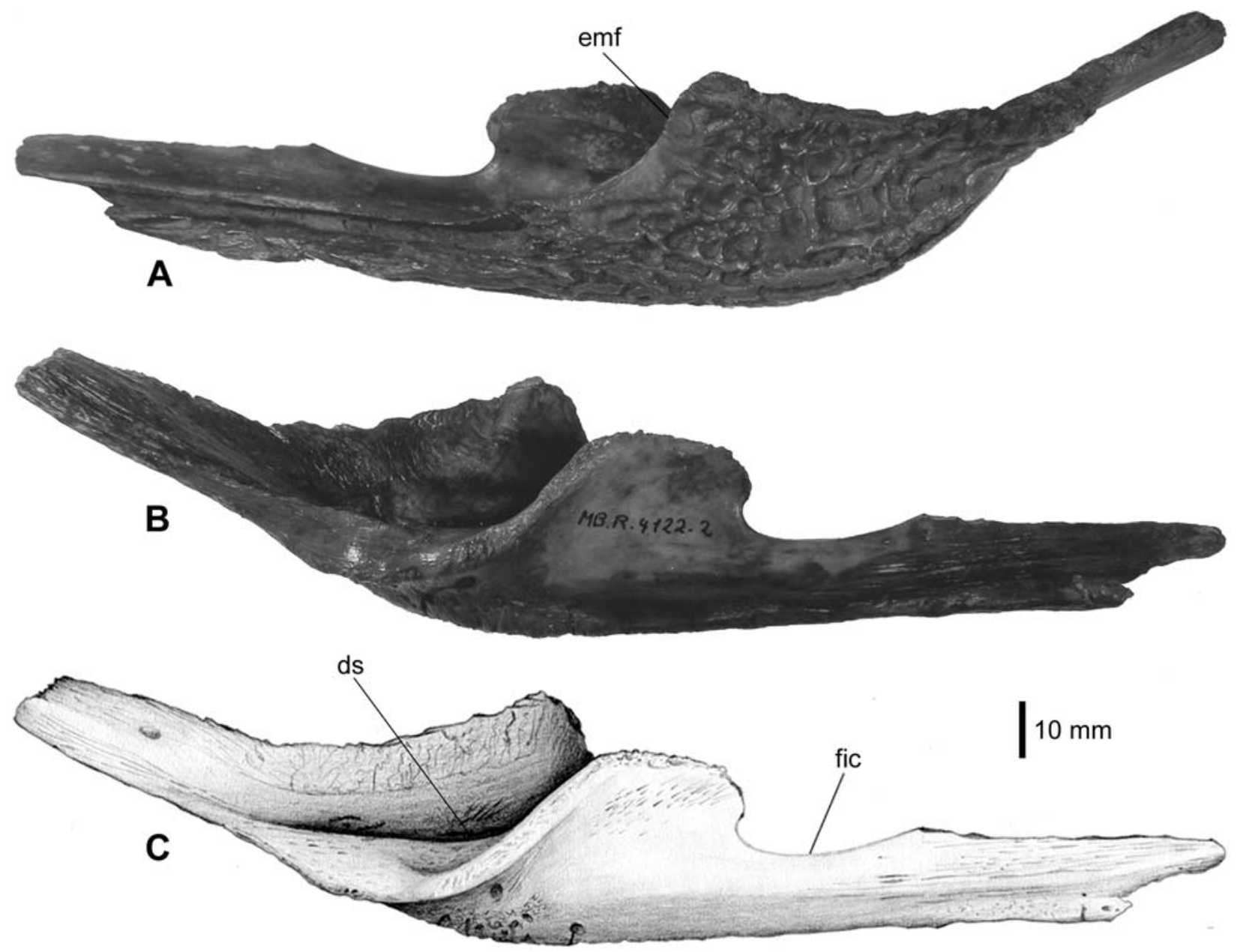

Figure 4. Left angular of specimen MB.R.4122.2, Voay robustus (Grandidier \& Vaillant, 1872). A. Photograph in external view. Note the external mandibular fenestra; B. Photograph in internal view; C. Drawing of B. Note the foramen intermandibularis caudalis; ds - deep sulcus; emf - external mandibular fenestra; fic - foramen intermandibularis caudalis. 
dentary, is visible (Brochu 2007). On its outer surface, the external mandibular fenestra is indicated (Fig. 4A). The suture with the surangular enters the external mandibular fenestra laterally at the posteriormost end. Internally, the foramen intermandibularis caudalis is indicated and the slender process anterior to it is rather short (Fig. 4B, C). Posterior to the foramen intermandibularis caudalis is a deep sulcus continuing into a dorso-posteriorly directed process. Below the deep sulcus, there are three small foramina. All sutures to adjacent bones are distinct and slightly jagged.

Postcranium. There are 40 vertebrae from different regions of the skeleton preserved, nine cervical vertebrae, 18 thoracic vertebrae, and 13 caudal vertebrae. All vertebrae are procoelous. The neural spines point directly upwards. Figure $5 \mathrm{~A}-\mathrm{F}$ shows two cervical vertebrae (MB.R.4093.4,5), two dorsal vertebrae (MB.R.4092.5,7), and two caudal vertebrae (MB.R.4090.2, 3). The cervical vertebrae (Fig. 5A, B) are proximodistally compressed and have high neural spines. The centra of the dorsal vertebrae (Fig. 5C, D) are twice as long as high. Unfortunately, here, the neu- ral spines are not preserved. The centra of the caudal vertebrae (Fig. 5E, F) are proximodistally elongate. The neural spines are not preserved in total length, but can be estimated to be approximately twice as high as the corresponding centra.

The two ribs seen in Figure 5G, H (MB.R.4114) consist only of the proximal parts, which have a massive appearance. They are double-headed. The suture with the vertebra is open, indicating that the ribs were not fused to the vertebrae. A keel heading dorsally is identifiable on the incipient shaft.

Altogether 25 osteoderms are preserved (MB.R.4097), originating from different regions of the dorsal armor. In Figure 5I-K, three of them are pictured. They are more or less square in outline and expose a highly pitted and sculptured dorsal surface. In the middle, there is a spiny process.

In Figure 6, a left (A) and a right (B) femur (MB.R.4107) are shown. Both are almost completely preserved. The distal end of the right one is incomplete. The left one measures $295 \mathrm{~mm}$ in length. They are very robust, revealing a thicker shaft than the humeri. Both ends are moderately expanded and the shaft
A
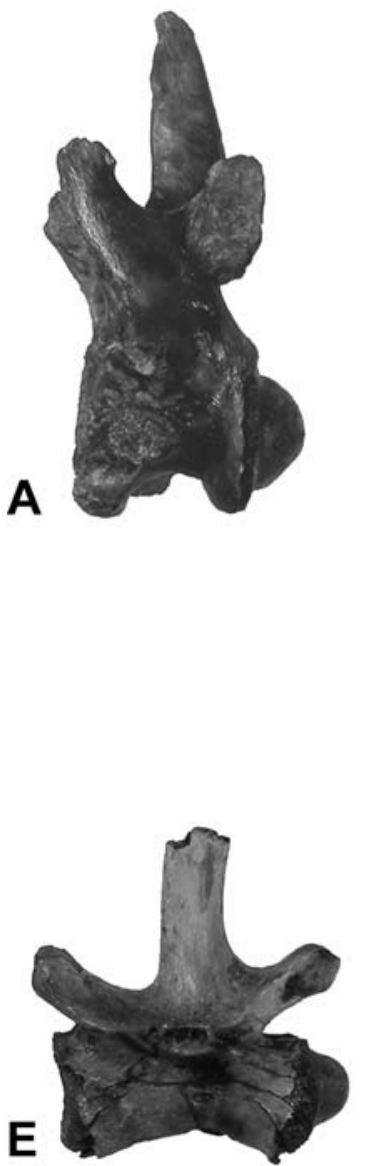
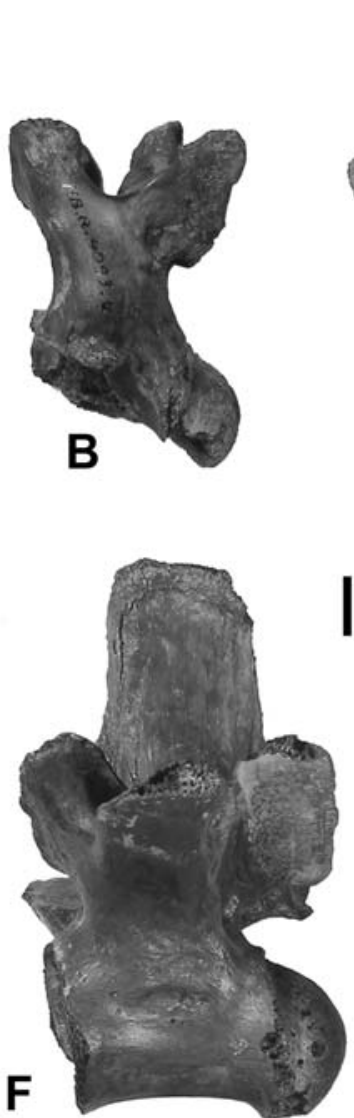

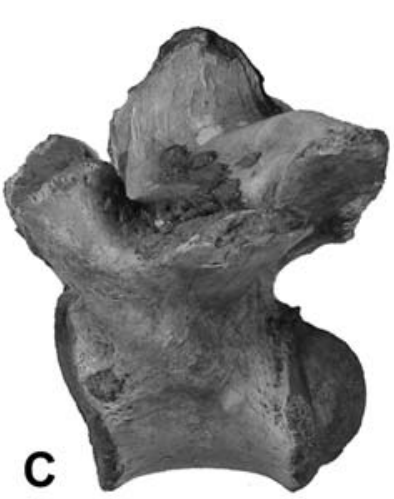

D
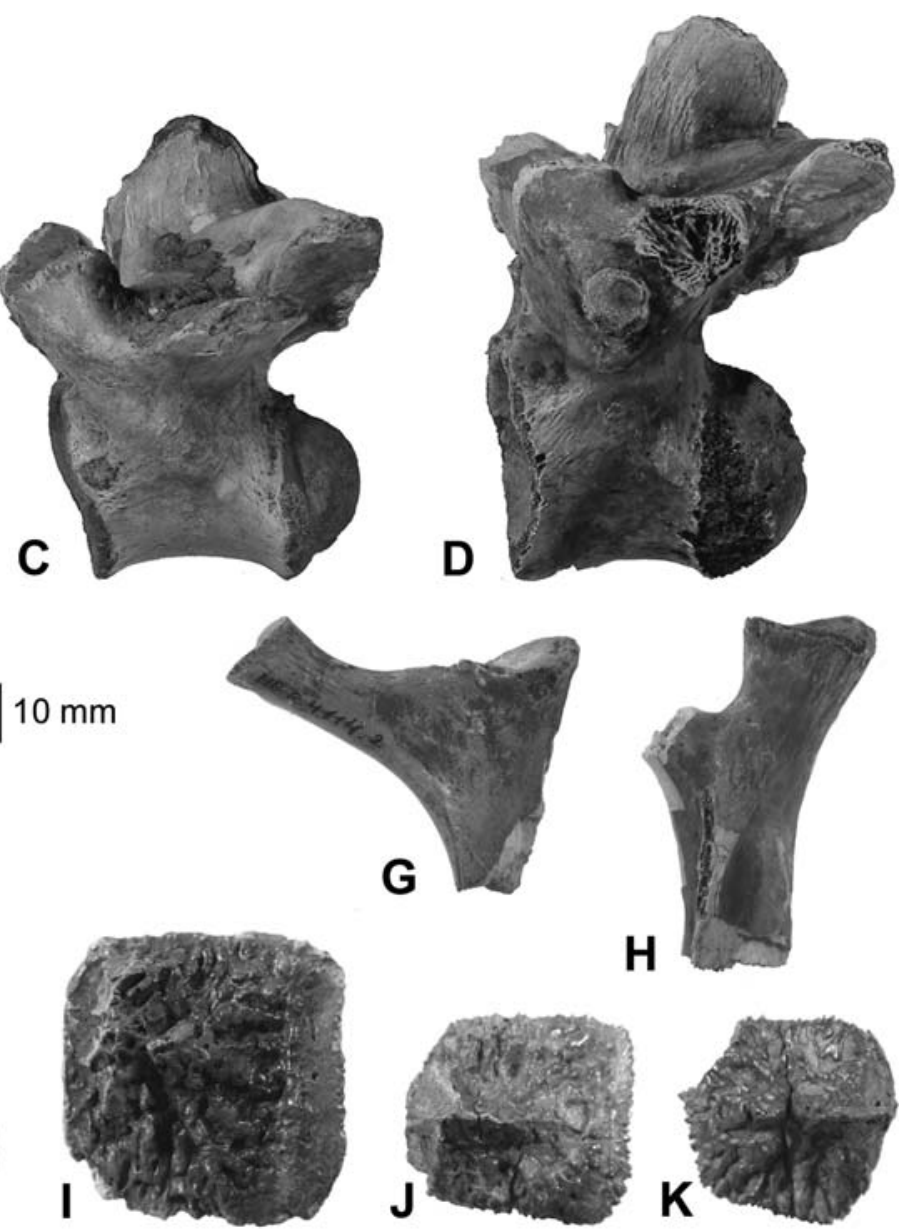

Figure 5. Photographs of several vertebrae of Voay robustus (Grandidier \& Vaillant, 1872). A-B. Photographs of cervical vertebrae in lateral view (MB.R.4093.4, 5); C-D. Photographs of dorsal vertebrae in lateral view (MB.R.4092.5, 7); E-F. Photographs of caudal vertebrae in lateral view (MB.R.4090.2,3); G-H. Photographs of ribs (MB.R.4114.1, 2); I-K. Photographs of osteoderms from different parts of the dorsal armour in dorsal view (belong to specimen MB.R.4097). 
is somewhat curved. The shaft surface is smooth, whereas the surface of both ends is covered by deep and long ridges. On the proximal head, which is dorsoventrally flattened, the fourth trochanter is prominent and its surface is textured. MB.R.4106-MB.R.4109 also represent femora. They are all of a similar size range.

MB.R.4112.1 represents the proximal part of a humerus (Fig. 6C). It is robust and exposes a prominent

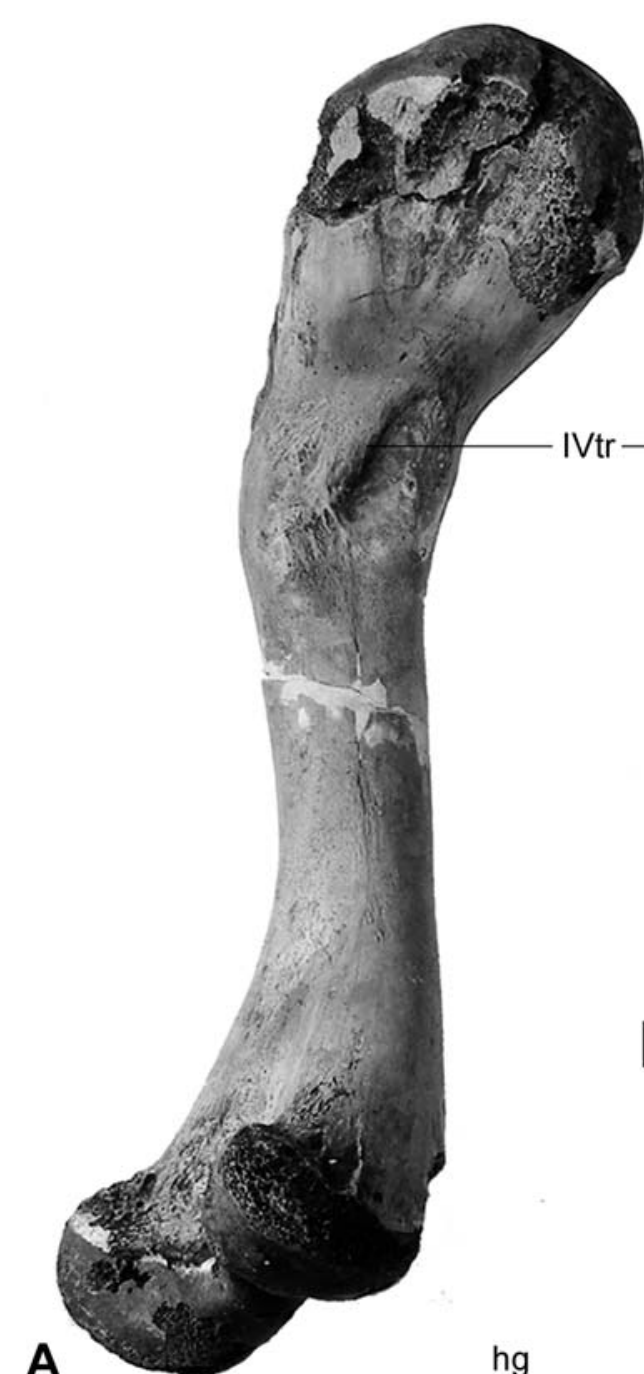

A
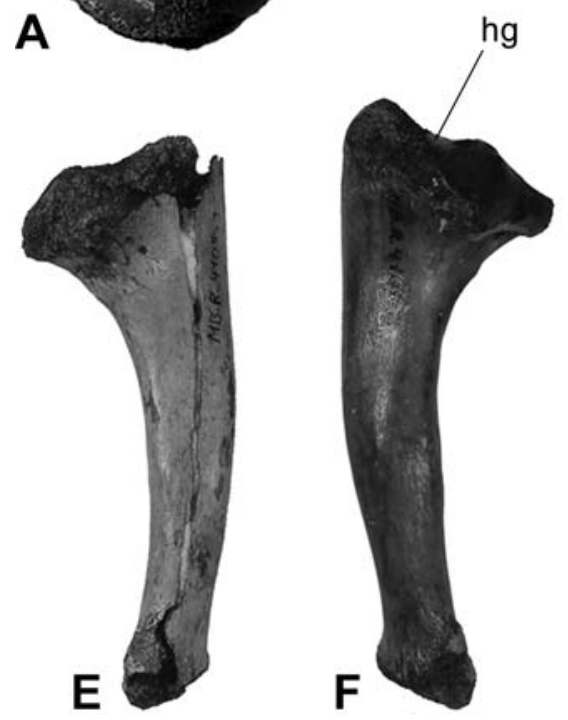

$\mathbf{F}$
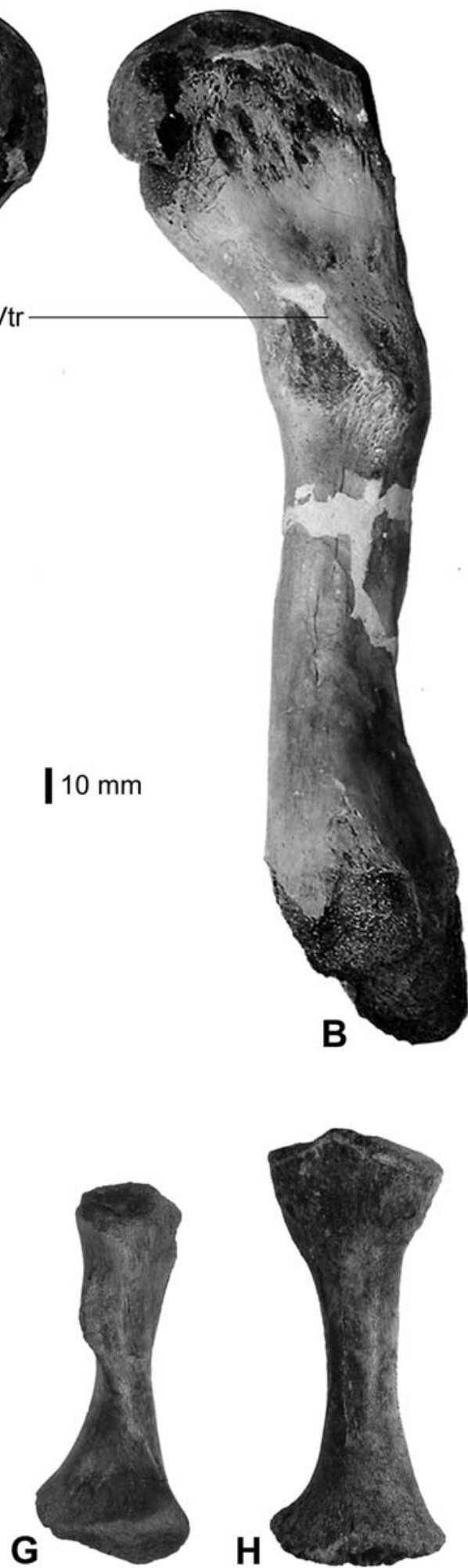
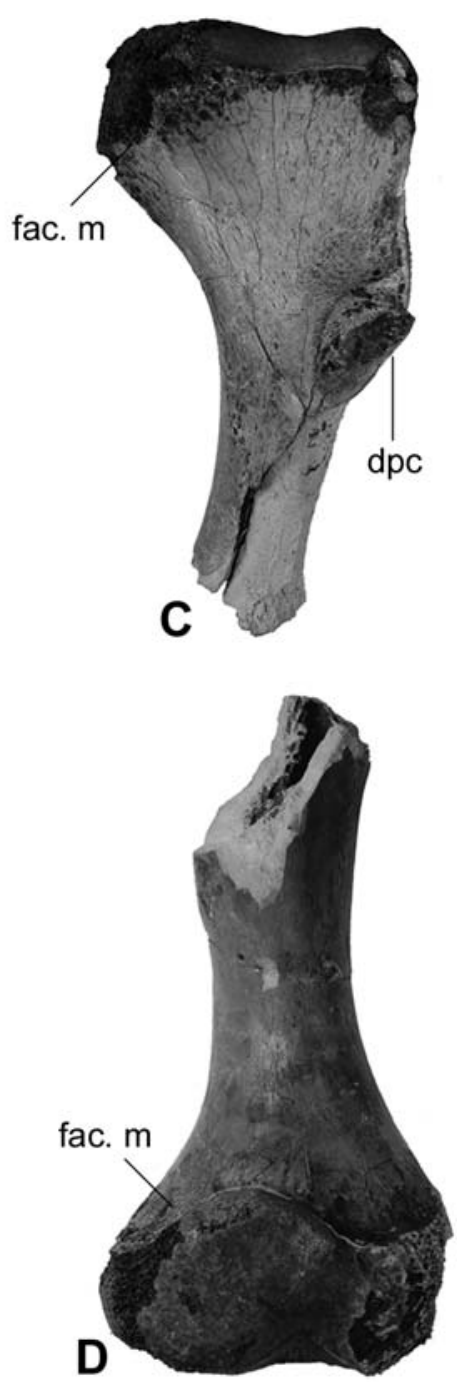

$\mathrm{H}$

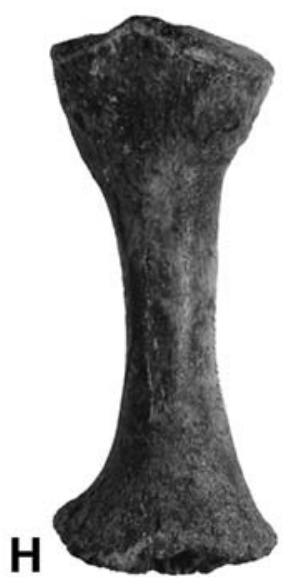

Figure 6. Photographs of different elements from the limbs of Voay robustus (Grandidier \& Vaillant, 1872). A-B. Both femora in ventral view (MB.R.4107.1, 2); C. Proximal part of humerus in ventral view (MB.R.4112.1); D. Distal part of humerus in ventral view (MB.R.4113); E-F. Left and right ulna in ventral view (MB.R.4105.1, 2); G-H. Two metacarpals (MB. uncatalogued); I-J. Two phalanges (belong to specimen MB.R.4110 and MB. uncatalogued); dpc - deltopectoral crest; fac. m - facet margin; hg humeral groove; IVtr - IVth trochanter. 
process, the deltopectoral crest, which is well developed. The facet margin is distinct. Distally follows a very slender and straight shaft, which is round in crosssection. The surface is covered by small pits and raised lines. MB.R.4113 comprises the distal end of a humerus (Fig. 6D). It is expanded and massive. The facet margin is distinct, and the articular condyles for the radius and ulna are not separate. Neither of the distal foramina is present. Here, the surface is smooth except for small ridges near the facet margins. Due to the different thickness of both shafts and differences in the color of the bones, they most likely represent two different individuals.

In Figure 6, a left (E) and a right (F) ulna (MB.R.4105) are depicted. Both are completely preserved, measuring 136 and $155 \mathrm{~mm}$ in length. The proximal head is robust and bears a prominent 'humeral groove' (sensu Brochu 2007). The facet margins are distinct. The shaft thins downwards to a non-broadened distal part. Overall, the surface is smooth, whereas the surface of the facets is partly weathered away.

Two metacarpals (both MB. uncatalogued) are preserved (Fig. 6G, H). Both ends are expanded. The shaft is straight and round in cross-section. The facet margins are recognizable. The surface is smooth. One (Fig. 6G) is $114 \mathrm{~mm}$ long. It has a notch for the attachment of muscles on the proximal end. The shaft is slightly turned in laterally. The distal end is more triangular in cross-section. The other one (Fig. 6H) is $137 \mathrm{~mm}$ long. Here, both ends are as rounded in cross-section as the shaft. The distal end is more robust than the proximal one.

Figure 6I, J show two completely preserved phalanges of similar size (MB.R.4110 and MB. uncatalogued). MB.R.4110 is $79 \mathrm{~mm}$ long (Fig. 6I), and the other one (MB. uncatalogued) is $83 \mathrm{~mm}$ long (Fig. 6J). They appear short and stout, and the surface is smooth. The shaft is rounded. Both ends are broadened, but still rounded in cross-section. The facet margins are undefined.

\section{Discussion}

The present material bears many features shared with the neotype and referred material of Voay robustus. As it has been suggested that Crocodylus niloticus was living in Madagascar contemporaneously with V.robustus (Burney et al. 1997), skull elements (ZMB 36650) were also observed for comparison.

The most prominent character shared by the neotype and referred material of $V$. robustus and the present material is the exposed squamosal horn, which is unique among osteolaemines (Brochu 2007). In detail, so far only $V$. robustus, the alligatorine Ceratosuchus, and a new finding of a giant horned crocodile from Tanzania share this character (Brochu et al. 2008). C. niloticus lacks this character.

Another diagnostic feature of $V$. robustus is the way the angular-surangular suture enters the external mandibular fenestra (Brochu 2007). In the MfN material
(MB.R.4122), the suture enters the foramen at the posteriormost end from lateral as in the neotype and referred material of $V$. robustus. Oval bosses on the anterior part of the frontal as stated by Brochu (2007) to be diagnostic for Voay are only seen on the right side in the MfN material. In C.niloticus, the frontal is much broader overall. Also, it lacks both oval bosses. In the MfN material, the lateral sides of the parietal also reach upwards as in the neotype of $V$. robustus. This character is not seen in C. niloticus.

The tooth formula in the lower jaw of $V$. robustus is consistent with that of $C$. niloticus, which usually contains 15 lower teeth (Iordanky 1973). Only one specimen of V.robustus exhibits only 14 teeth (Brochu 2007). In the MfN material (MB.R.4123), the dentaries also bear 14 alveoli each. However, alveolar counts can vary by one or two alveoli in most living species (Kälin 1933; Wermuth 1953; Iordansky 1973). In the MfN material (MB.R.4123), the third and fourth alveoli are not confluent as is also the case in the neotype and referred material of V.robustus (Brochu 2007). In C. niloticus, this character state is also present. As in the neotype and referred material of V.robustus, the 11th tooth in the lower jaw of the MfN material is also the largest tooth behind the fourth one. The dentary symphysis in the MfN material (MB.R.4121 and MB.R.4123) extends to the level of the sixth or seventh alveolus, meaning that it is as long as in the neotype and referred material of $V$. robustus where it extends also to the level of the seventh alveolus (Brochu 2007).

Concerning the postcranial material, the preserved vertebrae, ribs, osteoderms, femora, humeri, ulnae, metacarpals, and phalanges in the MfN collection match the neotype and referred material of $V$. robustus described by Brochu (2007) in morphology and size, except for minor differences that can be explained by individual variation.

Following are features that are inconsistent between the MfN material and the neotype and referred material of V.robustus. In the MfN material (MB.R.4123), the preserved teeth and alveoli are rounded-oval. In comparison, the teeth in the neotype and referred material of $V$. robustus are circular and not at all mediolaterally compressed (Brochu 2007). In C. niloticus, the teeth are similar in morphology. The different shape of the teeth in the MfN material is unlikely to be a result of taphonomy. Grandidier \& Vaillant (1872) state the angle of the mandibular symphysis for $V$.robustus to be fairly wide $\left(49^{\circ}\right)$. In the present material it measures $40^{\circ}$. In the specimen of $C$. niloticus used for comparison this angle amounts to $34^{\circ}$.

Thus, the MfN material shares three diagnostic characters with the neotype and referred material of $V$. robustus. Only two features are inconsistent, but minor differences between the MfN material and the material described by Brochu (2007) can be explained by intraspecific, ontogenetic, and/or sexual variation. Therefore, we argue that this material can be assigned to Voay robustus. 


\section{Ecological remarks}

Although there is not much data published on the fossil record of crocodylians from the Pleistocene (Brochu 2006, 2007), it seems unlikely that Voay robustus and Crocodylus niloticus occurred in Madagascar at the same time. This hypothesis is supported by two facts: first, findings of $C$. niloticus have not been found so far in the Pleistocene localities where V.robustus was found (Brochu 2007); second, according to results of molecular biological studies, the present-day population of . niloticus in Madagascar was established relatively recently (Schmitz et al. 2003). Both taxa were direct competitors due to their similarities in body size and shape, and their possible ecological preferences. Thus, from an ecological point of view, both crocodiles could not have coexisted over a long period of time without habitat partitioning. The question remains if $C$. niloticus displaced V.robustus or if it colonized Madagascar after Voay became extinct.

Brochu (2007) carefully concluded that the extinction of $V$. robustus was related to the arrival of humans and that $C$. niloticus invaded Madagascar only after suitable habitats were cleared of competing forms'. However, he also pointed to the lack of available data to support this hypothesis and did not exclude alternative scenarios (Brochu 2007). Contrary to Brochu, we think it is unlikely that a crocodile with a body length of nearly $4 \mathrm{~m}$ was regularly hunted and then eradicated by a few humans armed only with metallic tools like knives or axes. This hypothesis is also supported by Kuchling et al. (2004) who stated that the killing of large crocodiles took place only to a small extent before the arrival of Europeans in the 16th century. Moreover, C. niloticus was found in Madagascar in high densities until the early twenties of the 20th century (Kuchling et al. 2004). All these facts imply that Voay was not hunted to the point of extinction by humans.

Thus, we favour the hypothesis that $V$.robustus had become extinct due to changes in habitat and/or prey. In Early and Middle Pleistocene times, the central highlands of Madagascar were dominated by trees, shrubs and forbs (Burney et al. 2004). Then, in the late Pleistocene, changes in climate and vegetation took place and successively led to a transformation of the entire environment (Burney et al. 2004). However, once Voay was extinct, the Nile crocodile, which is a more flexible generalist, would have been able to establish a stable population in Madagascar.

If $C$. niloticus had in fact displaced Voay, we argue that both species would have been living contemporaneously, at least for a short period, and thus must be found together in the fossil record. This is not the case up to date. Therefore, we conclude that C. niloticus appeared in Madagascar after the extinction of Voay. However, it is possible that sporadic immigration of individuals of $C$. niloticus from the African continent might have taken place during the Pleistocene.

\section{Acknowledgements}

We are grateful to Markus Brinkmann (Berlin) for preparation of the specimens. Constanze Bickelmann is thankful to Daniela SchwarzWings (Berlin) and Johannes Müller (Berlin) for access to the MfN collection, as well as to Mark-Oliver Rödel (Berlin) and Detlev Langer (Berlin) for access to the Crocodylus niloticus specimen. Also, we are thankful to Karen E. Samonds (New York) and David Burney (New York), who provided us with information and literature about the Pleistocene of Madagascar. We thank Christopher Brochu (Iowa City), Inken Mueller-Töwe (Copenhagen), Kristian Remes (Bonn), Linda Tsuji (Berlin), and an anonymous reviewer for their remarks that improved earlier versions of the manuscript. Constanze Bickelmann was financially supported by DFG project Mu 1760/2-3.

\section{References}

Brochu, C. A. 2000. Phylogenetic Relationships and Divergence Timing of Crocodylus based on Morphology and the Fossil Record. Copeia 3: 657-673.

Brochu, C. A. 2001. Crocodylian Snouts in Space and Time: Phylogenetic approaches toward adaptive radiation. - American Zoologist 41: 564-585.

Brochu, C. A. 2003. Phylogenetic approaches toward crocodilian history. - Annual review of Earth and Planetary Sciences 31: 357397

Brochu, C. A. 2006. A new miniature horned crocodile from the Quaternary of Aldabra Atoll, western Indian Ocean. - Copeia 2: 149-158.

Brochu, C. A. 2007. Morphology, relationships, and biogeographical significance of an extinct horned crocodile (Crocodylia, Crocodylidae) from the Quaternary of Madagascar. - Zoological Journal of the Linnean Society 150: 835-863.

Brochu, C., Blumenschine, R. \& Densmore, L. 2008. Giant horned crocodiles from the late Cenozoic of Africa: stealth diverity revisited. - Journal of Vertebrate Paleontology 28 (3): 57 A

Burney, D. A., James, H. F., Grady, F. V., Rafamantanantsoa, J.-G., Ramilisonina, Wright, H. T. \& Cowart, J. B. 1997. Environmental change, extinction, and human activity: evidence from caves in NW Madagascar. - Journal of Biogeography 24: 755-767.

Burney, D. A., Burney, L. P., Godfrey, L. R., Jungers, W. L., Goodman, S. M., Wright, H. T. \& Jull, A. J. T. 2004. A chronology for late prehistoric Madagascar. - Journal of Human Evolution 47: $25-63$.

Cuvier, G. 1807. Sur les différentes espèces de crocodiles vivans et sur leurs caractères distinctifs. - Annales du Muséum d'Histoire Naturelle de Paris 10: 8-66.

Farlow, J. O., Hurlburt, R. M. E. G. R., Britton, A. R. C. \& Langston, Jr. W. 2005. Femoral dimensions and body size of Alligator mississippiensis: Estimating the size of extinct mesoeucrocodylians. - Journal of Vertebrate Paleontology 25 (2): 354-369.

Glaw, F. \& Vences, M. 1994. A Field Guide to the Amphibians and Reptiles of Madagascar. Vences \& Glaw Verlag, Köln.

Goodman, S. M. \& Ravoavy, F. 1993. Identification of bird subfossils from cave surface deposits at Anjohibe, Madagascar, with a description of a new giant Coua (Cuculidae: Couinae). - Proceedings of the Biological Society 106: 24-33.

Grandidier, A. 1872. Description de quelques reptiles nouveaux découverts à Madagascar en 1870. - Annales des Sciences Naturelles (Zoologie et Biologie Animal) 15: 6-11.

Grandidier, A. \& Vaillant, L. 1872. Sur le crocodile fossile d'Amboulintsatre (Madagascar). - Comptes Rendus de l'Académie des Sciences de Paris 75: 150-151.

Iordansky, N. N. 1973. The skull of the Crocodilia. In Gans, T. P. C. (ed.). Biology of the Reptilia. Academic Press, London: pp. 201-260. 
Kälin, J. 1933. Beiträge zur vergleichenden Osteologie des Crocodilidenschädels. - Zoologische Jahrbücher 57: 535-714.

Kuchling, G., Lippai, C. \& Behra, O. 2004. Crocodylidae: Crocodylus niloticus, Nile crocodile, Voay, Mamba. In Goodmann, S. M. \& Benstead, J. P. (eds). Natural History of Madagascar. University of Chicago press, Chicago: pp. 1005-1018.

Laurenti, J. N. 1768. Specimen Medicum, Exhibens Synopsin Reptilium Emendatum cum Experimentatis Circa Venena et Antiodota Reptilium Austriacorum. J. T. de Trattern, Vienna.

Mook, C. C. 1921. Description of a skull of the extinct Madagascar crocodile, Crocodilus robustus Vaillant and Grandidier. - Bulletin of the American Museum of Natural History 44: 25-31.

Owen, R. 1842. Report on British fossil reptiles. Part II - Reports of the British Association for the Advancement of Science 11: 60-204
Romer, A. S. 1956. Osteology of the Reptiles. University of Chicago Press, Chicago and London.

Samonds, K. E. 2007. Late Pleistocene bat fossils from Anjohibe Cave, northwestern Madagascar. - Acta Chiropterologica 9 (1): $39-65$.

Tumarkin-Deratzian, A. R., Vann, D. R. \& Dodson, P. 2006. Bone surface texture as an indicator in long bones of the Canada goose Branta canadensis (Anseriformes: Anatidae). - Zoological Journal of the Linnean Society 148: 133-168

Schmitz, A., Mansfeld, P., Hekkala, E., Shine, T., Nickel, H. G. \& Amato, B. W. 2003. Molecular evidence for species level divergence in African Nile crocodiles Crocodylus niloticus (Laurenti, 1786). - Comptes Rendus Palevology 2: 703-712.

Wermuth, H. 1953. Systematik der rezenten Krokodile. - Mitteilungen des Zoologischen Museums Berlin 29: 376-514. 